\title{
A VIDA SOCIAL DE UM EMBLEMA NACIONAL: O CASO DO SABRE DO GENERAL JOSÉ DE SAN MARTÍN (1778-1850)*
}

Andrea Roca

\section{Introdução}

Consagrado pela historiografia oficial como o maior herói militar nacional, e invocado até hoje com expressões tais como "Libertador da América", "Pai da Pátria" ou "Santo da Espada", a figura do General José de San Martín (1778-1850) possui um peso significativo na cultura e na política argentinas. A necessidade do Estado de construir esta figura histórica emblemática foi articulada principalmente a partir de dois ângulos: em primeiro lugar, destacando a grandeza de suas façanhas militares, já que a vitória em suas batalhas foi decisiva para alcançar a independência política da Argentina, do Chile e do Peru; em segundo lugar, tornando a pessoa de San Martín um exemplo ético, que preferiu se retirar da cena política em pleno apogeu por não querer derramar "sangue argentino" em guerras civis, como as que aconteceram depois.

Enquanto isso, o sabre que o acompanhou em todas as batalhas pela independência desses três países foi considerado como uma extensão da figura do seu dono, ficando assim vinculado ao tempo mítico da história, à origem da nação. Desde 1967, essa "relíquia histórica" está custodiada por uma instituição militar: o chamado Regimiento de Granaderos a Caballo, corpo de cavalaria do Exército Argentino criado em 1812 pelo próprio San Martín (e, desde 1907, grupo militar responsável pela escolta presidencial dentro do país). Os granaderos também custodiam permanentemente o túmulo do herói, localizado na Catedral Metropolitana, na cidade de Buenos Aires.

O sabre encontra-se na área museológica do Regimiento de Granaderos a Caballo, ${ }^{1}$ mas, pelo fato de fazer parte de uma dependência militar, essa área está fechada para o público. Quem quiser conhecer a famosa peça histórica tem que solicitar, por escrito, uma autorização do chefe do Regimiento para realizar uma visita. 
Uma vez autorizado, o visitante deverá registrar-se na portaria e nela deixar depositada a sua carteira de identidade, que ficará retida durante o breve percurso por este museu militar. A seguir, será conduzido por alguns granaderos pelas amplas escadas de pedra do elegante prédio, ingressando logo no seu hall central. Nele, será envolvido pelas luzes coloridas de um gigantesco vitral que filtra suavemente a luz natural, iluminando tudo quanto há no recinto: os bronzes das ferragens, os cristais das lâmpadas, os mármores do chão, das colunas e das escadas. Nessa espécie de palácio, tudo brilha.

Na parede esquerda desse ambiente imponente, chamado "Hall de los Grandes Símbolos Sanmartinianos", há um conjunto de quatro vitrines embutidas na parede, custodiado por dois granaderos em ambos os lados. Entre elas, a que mais chama a atenção é aquela que guarda uma imagem da Virgem de Carmen de Cuyo, padroeira do chamado Ejército de los Andes (criado e liderado pelo General San Martín). A estátua da Virgem veste uma banda argentina, e está acompanhada pelas bandeiras argentina, chilena e peruana - isto é, os três países libertados pelo herói. Acima dessa vitrine podemos ler:

Nossa Senhora de Carmen de Cuyo. Proclamada pelo General San Martín Padroeira e Generala do Exército dos Andes em 5 de janeiro de 1817. Coroada por decreto de S.S. Pio X em 6 de setembro de $1911 .^{2}$

Abaixo da imagem da Virgem encontra-se a vitrine blindada por motivo de segurança que protege e exibe o sabre, com a sua bainha; acompanha-o uma placa de bronze que reproduz a cláusula terceira do testamento do General San Martín, à qual retornaremos oportunamente. Mais abaixo ainda, duas vitrines menores mostram dois cofres pequenos: um deles contém terra de São Lourenço, local onde teve lugar uma das mais importantes batalhas vitoriosas contra os espanhóis pela independência da Argentina; o outro cofre possui terra da casa natal do herói (localizada em Yapeyú, província de Corrientes). Em ambos os lados desta espécie de altar católico, os dois granaderos, imóveis, custodiam esta peça de veneração histórica que, aparentemente, simbolizaria e/ou deteria certos valores nacionais defendidos por San Martín. Como será apresentado a seguir, segundo a historiografia oficial, tratar-se-ia de valores aparentemente unívocos e sem contradições.

Comprado pelo próprio San Martín em Londres, o sabre, além de pertencer-lhe, acompanhou-o em toda a sua carreira militar e esteve com ele até o último dos seus dias: essa relação de contiguidade é o ponto de partida do seu valor social e, supostamente, conseguiria explicar a aura sa- 
grada que parece rodear este objeto. Por causa dessa mesma contiguidade, a localização do sabre no Regimiento de Granaderos pode parecer lógica e/ou transparente: ele é protegido pelos soldados criados por San Martín, honrando-se mutuamente. ${ }^{3}$

Não obstante, uma análise da trajetória social deste sabre nos permitirá iluminar os sinuosos caminhos percorridos por este objeto - comprado, utilizado e conservado por San Martín — até chegar àquele Regimiento: basicamente um sabre fabricado na Inglaterra, no começo do século XIX, encontra-se hoje semiexibido em Buenos Aires; desde 1967 está no meio de um altar e dentro de uma vitrine blindada, custodiado por granaderos e fora do circuito das exposições para o grande público; nunca mais foi utilizado para o propósito com o qual havia sido criado e, além disso, é conservado e exposto como uma relíquia sagrada. Como tentaremos expor a seguir, a sua história vincula pessoas, cidades, datas, instituições, acontecimentos, projetos políticos etc., adquirindo, em cada fase da sua biografia e/ou "vida social" (Appadurai 1986; Kopytoff 1986), atributos que incrementaram seu valor e sua significação.

Aliás, o caráter emblemático do sabre, isto é, seu poder distintivo enquanto representação, como marca de identidade de um grupo (Durkheim 1968), concentra lutas de representações e classificações pelo estabelecimento de histórias e identidades, e reúne também as lutas pela legitimidade dessas histórias e identidades, acompanhadas pelas consequentes produções de bens simbólicos nesses campos políticos (Bourdieu 1998). Aceitar as possibilidades de transformação dos objetos é reconhecer neles a existência de processos através dos quais podemos distinguir a produção social de tais transformações (Thomas 1991): essas mudanças apresentam-se como as formas e os efeitos "visíveis" de tecidos de relações sociais, mantidas ao longo de diferentes processos políticos que, ao serem analisados, questionam e modificam profundamente qualquer significado unívoco atribuído ao sabre-relíquia.

O propósito deste trabalho será, portanto, identificar e analisar esses percursos. Para isso, dividirei este artigo em duas partes. Na primeira delas (A agitada vida social de um sabre), apresentarei as passagens deste particular objeto de culto nacional entre as pessoas, os lugares e as instituições que, sucessivamente e até hoje, administraram a custódia deste objeto, e os seus significados; ao mesmo tempo, analisarei como, inseridas por sua vez em contextos particulares, as relações sociais tecidas em torno do sabre transformaram e redefiniram seu valor através de particulares redes de intercâmbios, reciprocidades e interdependências. A partir desse exame e da problematização das características atribuídas ao sabre ao longo do tempo, na 
segunda parte (Objetos para amar a pátria), indagarei sobre as possibilidades abertas pela pesquisa antropológica sobre os objetos, especificamente sobre aqueles que integram os chamados "patrimônios históricos nacionais" ${ }^{4} \mathrm{em}$ torno das dimensões imateriais que parecem acompanhar esses acervos.

\section{A agitada vida social de um sabre}

Com o propósito de organizar esta espécie de biografia, ela foi dividida em três períodos: o primeiro deles (San Martín, seu sabre e seu problemático testamento) começa com a aquisição do sabre em 1811 e vai até o seu ingresso no Museu Histórico Nacional (1897), em torno de uma sucessão de doações; o segundo período (O sabre de San Martín e o Museu Histórico Nacional) é dedicado à permanência do sabre neste Museu, de 1897 até 1963; a terceira parte (Um sabre sequestrado como refém) compreende os "desaparecimentos" do sabre, assim como as lutas posteriores por sua propriedade e relocalização.

\section{San Martín, seu sabre e seu problemático testamento}

San Martín compra seu sabre em Londres, em 1811, voltando com ele a Buenos Aires no ano seguinte. Esta arma acompanhou-o nas Guerras pela Independência, travadas contra os espanhóis entre 1812 e 1823, período que também inclui as batalhas - comandadas por ele - que deram independência política ao Chile e o Peru. Depois da famosa e enigmática "Entrevista de Guayaquil" com Simón Bolívar, San Martín desaparece da cena militar e, em 1824, parte para França, deixando seu sabre sob os cuidados de uma família amiga, na província de Mendoza. Em 1835 escreve uma carta a seu genro, na qual, entre outras coisas, solicita-lhe o envio do sabre, que o leva para a França pessoalmente, em 1837. Em janeiro de 1844 (seis anos antes do seu falecimento), San Martín redigiu seu testamento; a cláusula terceira rezava:

[o sabre] será entregue ao General da República Argentina Dom Juan Manuel de Rosas, como uma prova da satisfação que tenho tido, como argentino, ao ver a firmeza que ele teve para manter a honra da República, contra as injustas pretensões dos estrangeiros que tentaram humilhá-la (Otero 1932:390-391; Ramallo 1995:29; Ortiz de Rozas 1950:4). 
Diferentemente do culto historiográfico à figura de San Martín — tanto como herói militar quanto como exemplo ético ${ }^{5}$ - o General Juan Manuel de Rosas (1793-1877) é, até hoje, uma das figuras políticas mais polêmicas da história argentina. Foi governador de Buenos Aires nos períodos 1829-1832 e 1835-1852, e apresentava-se como o mais genuíno representante dos setores federais: estes pretendiam governos quase autônomos para cada estado liderados cada um deles pelos chamados caudilhos - e, ao mesmo tempo, reclamavam a descentralização de Buenos Aires. Rosas era o oponente declarado dos setores unitários, os quais estavam organizados, na maioria, em torno de uma elite aristocrática que, laica e liberal, respondia aos modernos modelos de nação importados da Europa ${ }^{6}$ A partir da derrota de Rosas na Batalha de Caseros, em 1852, os setores unitários/liberais ficaram à frente da organização nacional; a sua presença no governo do país se estenderia até, pelo menos, as duas primeiras décadas do século XX.

Após o triunfo unitário, Rosas exilou-se em Southampton, Inglaterra, conservando com ele o sabre de San Martín. Por pedido expresso de Rosas, na hora da sua morte (1877), foi colocado em cima do seu féretro, junto a uma bandeira argentina, o sabre de San Martín. ${ }^{7}$ Este foi entregue por testamento a seu melhor amigo, Juan Terrero. Na mesma cláusula, Rosas apontava que, caso este morresse, deveria transferi-lo a seu filho mais velho. E assim aconteceu. Coincidentemente, o primogênito Máximo Terrero era casado com a única filha de Rosas, Manuelita, razão pela qual, em 1885, o sabre se encontrava novamente com a família Rosas.

Convém determo-nos aqui para organizar alguns apontamentos, que começam pela aquisição do sabre: foi "comprado" pelo próprio San Martín em uma loja de armas londrina; tratava-se, claramente, de um sabre como mercadoria, um bem alienável e anônimo, com um preço de venda no mercado. Entretanto, o fato de ter estado com San Martín nas batalhas vitoriosas que marcariam para sempre a história do jovem país produziu uma primeira modificação do seu valor, ficando unido à figura do seu dono e tendo recebido seu nome.

O próprio San Martín considerava seu sabre como um objeto valioso: sabendo-se transcendental ${ }^{8}$ - e assumindo que seus objetos também o eram entregou seu sabre como uma demonstração de gratidão a quem, como ele, tinha defendido a soberania do seu país, reconhecendo deste modo a gestão de Rosas e oferecendo-lhe o sabre como "prova de satisfação". San Martín tinha conservado seu sabre: este fazia parte do seu patrimônio, e foi cedido através de um testamento, isto é, um documento que expressava sua vontade e que apontava um lugar determinado para todos os seus pertences quando chegasse a hora de passar à imortalidade, com o que já contava. 
Mas o que San Martín doava a Rosas junto com este objeto? O sabre resultava útil como "medida de reconhecimento" de um alto chefe militar para outro, aprovando assim uma gestão política, ou seja, era uma doação constituída por um objeto acrescido de um significado, definido pelo próprio San Martín, dando assim início à vida simbólica do sabre: objeto e significado foram aceitos por Rosas. ${ }^{9}$ A relação criada entre eles pela passagem do sabre era também de prestígio político, o que afetou profundamente o cenário da época em função de a atitude de San Martín implicar uma aprovação do governo de Rosas em detrimento dos setores unitários. Tanto as críticas que San Martín recebeu por este ato quanto os esforços dos unitários para desautorizar os motivos que ele próprio estabelecera na controversa "cláusula terceira" tornam manifesto como esta doação consolidava uma relação não só pessoal, mas também política. Pelo fato de ser incompatível com a escrita da história, feita por liberais, essa relação deveria ser eclipsada e, para isso, apelava-se para que fosse desqualificada a doação. ${ }^{10}$

Em 1896, Adolfo P. Carranza - que era, na época, diretor do Museu Histórico Nacional da República Argentina - escreveu uma carta a Manuelita Rosas, solicitando-lhe a doação do sabre para o acervo deste museu.

\section{O sabre de San Martín e o Museu Histórico Nacional}

Antes de continuar com os novos percursos do sabre em terras americanas, precisamos abrir um extenso parêntese para nos referirmos ao Museu Histórico Nacional (doravante, MHN). Foi criado em 1889 por quem fora seu primeiro diretor, Adolfo P. Carranza (1857-1914), com o propósito de "evocar as tradições da Revolução de Maio e das Guerras da Independência, no contexto da modernização da sociedade argentina através da imigração massiva". ${ }^{11}$ O MHN foi uma das muitas atividades do Estado, responsável por configurar e estabelecer uma imagem de nação a partir da qual seria projetado o genérico nós - imprescindível no processo de formação dos Estados Nacionais. Imitando as instituições da moderna Europa e atendendo à imperiosa necessidade de unificar valores e identidades perante o desejo e a ameaça da imigração, o MHN se constituiria em uma peça-chave no quebra-cabeças cultural da época pelo fato de albergar, em sua arquitetura, "a" história do jovem país.

Através dos objetos ali reunidos, o Museu tinha condições de existência e visibilidade que, com outras expressões da nação, contribuiriam para 
construir "a Argentina" como noção totalizadora. A necessidade de fazer uma nação "imaginável", através de uma linguagem museológica, implicou administrar uma determinada maneira de ser dos objetos exibidos, organizando com eles conjuntos patrimoniais que, aparentemente, formavam um campo direto de comunicação com a assim chamada história nacional. A criação do MHN respondia também à necessidade de contar com um museu para a futura celebração do Centenário, em 1910: para essa ocasião, Carranza aspirava reunir um acervo importante e representativo "dos homens que fizeram a Pátria". ${ }^{12}$

Membro da elite dominante do seu tempo, ${ }^{13}$ Carranza dedicou toda a sua gestão (1889-1914) à procura incessante de objetos, aproveitando sua rede de relações sociais e administrando pessoalmente tais aquisições. ${ }^{14}$ Para um museu que tentava reconstruir os eventos das Guerras da Independência, o sabre do seu principal protagonista havia de ser considerado um elemento importante nessa reconstrução: era necessário, então, solicitar o valioso objeto a seus donos naquele momento. Assim o fez Carranza, através de uma carta enviada à filha de Rosas na Inglaterra, em setembro de 1896. A citação é parcial:

Entre as manifestações de aplauso que ele [Rosas] recebeu [...] é, sem dúvida, da maior importância, aquela que mereceu do ilustre General San Martín [...] a República Argentina, constituída através de quase um século de dolorosa anarquia, possui um estabelecimento onde se reúnem e guardam as lembranças de épocas e homens que pertencem à história [...] Eu me permito solicitar à Senhora [...] aquele sabre redentor de um mundo, para que aqui, no seio da pátria que lhe deu o ser, possa ser contemplado pelos que habitam esta terra; que o sabre os inspire para defender a soberania nacional, tal como aconteceu na ocasião que originou a cessão do sabre para o Senhor seu pai. Considero que nada seria mais satisfatório para a Senhora do que obter o agradecimento dos cidadãos, e, neste caso, te-lo-á, porque seria bom para a memória do Senhor seu pai entregar à pátria o que é dela... [...] Animado de propósitos patrióticos e persuadido de que não apelo em vão a um sentimento pela terra dos seus amores e dos seus descendentes, terra que deve latejar, perene, no seu coração, venho a rogar à Senhora que faça uma doação ao "Museu Histórico", em nome do Senhor seu pai, do sabre que ele recebeu como prova de satisfação pela firmeza que teve para defender a honra da República [...] (Quesada 1902:70-72; Ramallo 1995:38-39. Grifo meu).

Manuelita Rosas respondeu a Carranza em novembro de 1896; também aqui a citação é parcial: 
Oportunamente recebi sua fina carta [...] tão interessante pela justiça que o Senhor faz, nela, a respeito da atitude heroica [de Rosas]. Por disposição do testamento do meu pai, o sabre [...] que o Senhor me pede com palavras tão gratas, para destiná-lo ao Museu Histórico Nacional do nosso país, atualmente pertence ao meu marido e, como facilmente o Senhor compreenderá, custa-lhe muito, como a todos nós, fazer o sacrifício de desprendermo-nos dele. [...] Mas, finalmente, o meu marido, com a inteira aprovação minha e dos nossos filhos, decidiu-se em doar à "Nação Argentina" este monumento de glória para ela, reconhecendo que o verdadeiro lar do sabre do Libertador deve ser o seio do país que ele libertou [...] (Quesada 1902:74-75; Ramallo 1995:40-41. Grifos meus).

O consentimento desta doação estava, entretanto, acompanhado de uma condição: Manuelita exigia que seu sobrinho, Juan Manuel Ortiz de Rosas (neto do General), recebesse o sabre quando este chegasse a Buenos Aires; aliás, Manuelita escreve a seu sobrinho pedindo-lhe que se ocupe da exibição do sabre no MHN: a peça devia ser colocada junto com "a cláusula terceira".

A chegada do sabre a Buenos Aires concretiza-se em fevereiro de 1897, tendo sido recebido pelo neto de Rosas, que o entregou ao presidente da nação, José E. Uriburu, em 4 de março. O evento foi realizado no MHN, e caracterizou-se pela ausência das principais figuras políticas ${ }^{15}$ e também da cúpula militar. ${ }^{16}$

É impossível tornar inteligível essa sucessão de acontecimentos sem acompanhar os atores e reconstruir o xadrez social da época; deste modo, interrogar os documentos nos permite aproximarmo-nos deles, para assim tentar identificar o que se estava intercambiando e por que, entre quem e por quais motivos - perguntas todas que precisam ser respondidas em termos históricos e locais.

Como pudemos ler no documento, Carranza está "rogando" uma doação; pede o objeto valioso em troca do reconhecimento da defesa da soberania nacional, o mesmo reconhecimento expresso a Rosas por San Martín. Não obstante, o pedido está impregnado de um forte caráter coercitivo pelo fato de exigir, ao mesmo tempo, a "devolução" de algo que, segundo ele, "pertence à pátria". Para começar, não foi "a pátria" quem entregou o sabre a Rosas, e sim San Martín; entretanto, "a pátria" foi "quem deu o ser" ao sabre e, por isso - com uma ontologia própria - deve-se a ela e à história, invocandose assim uma inalienabilidade em face do povo argentino que questiona, implicitamente, o lugar de Manuelita Rosas como legítima proprietária. Em segundo lugar, a "obrigação" apontada por Carranza coloca nos ombros de Manuelita uma obrigação perante "a pátria", obrigação que será reconhecida "pelos cidadãos", isto é, ela é confrontada com o possível juízo da opinião 
pública. Por último, o pedido torna-se uma espécie de suborno pelo fato de insinuar que "seria pelo bem da memória do seu pai": nas mãos dos liberais, a história tinha desprestigiado a imagem de Rosas, motivo pelo qual aquilo que era oferecido por Carranza - melhorar a memória de Rosas em troca do sabre - teria sido, para Manuelita, uma promessa valiosa.

Podemos conjeturar que a linguagem afetiva da carta, apelando a Manuelita em seu papel de "filha", teria contribuído para reafirmar esta possibilidade. Pensemos nos termos de ambas as correspondências: a obrigação de "devolução", instalada por Carranza, é traduzida por Manuelita como um ato de sacrifício, não somente "como argentina, para os outros cidadãos", mas também "como filha, para seu pai", já que obteria, em troca, a redefinição da sua memória: Rosas entraria - e nada menos que pela mão de San Martín — no MHN, "templo do imortal". ${ }^{17}$ A obtenção deste reconhecimento poderia explicar a dimensão do seu desprendimento, formulado em termos de "sacrifício".

Por que o sabre de San Martín era importante, além do valor pessoal que tinha para o herói? Devemos levar em consideração que a história argentina foi escrita principalmente por Vicente Fidel López e Bartolomé Mitre, ambos liberais e maçons: em seus textos, tinham glorificado a imagem de San Martín. Se não era possível desfazer o dito, pelo menos podia-se recuperar um elemento que eles mesmos tinham destacado como valioso, para utilizá-lo na ilustração da bela história traçada no MHN.

Por que Carranza exigia uma doação, em vez de solicitar o sabre em troca de dinheiro? Em segundo lugar, qual o significado deste pedido, caso se resolvesse com sucesso? Quanto à primeira pergunta, poderíamos responder que o sabre já era, nesse momento, um objeto com história, valioso por significados pessoais e também históricos, ficando, por isso, fora do circuito econômico. Mas tem algo a mais, e que responde inclusive à segunda questão: embora a sua posse, por si só, já constituísse um valor, o fato da doação a incrementava porque, do outro lado, quem estava "devolvendo à pátria o que era dela" era nada menos que a filha de Rosas; deste modo, a propriedade do sabre também significava uma vitória dos unitários sobre os federais, pelo fato de se apropriarem de um objeto que tinha sido transmitido para legitimar uma ação política da oposição - conservar o sabre era arrogar-se uma autoridade, anulando outra. Se o sabre possuía valor simbólico devido a seu significado político, era necessário, então, selecionar e redefinir os alcances de tal significado.

A chegada à Argentina marca uma disjunção: veio o sabre, mas não os significados que eles esperavam por causa da presença do neto de Rosas. A ausência das figuras mais influentes do panorama político denota a nega- 
ção dos laços que teriam se estabelecido só pelo fato de estarem ali, presentes; além disso, torna manifesto quanto era importante a forma da recepção, pelo fato de proporcionar uma nova oportunidade na qual delinear seu significado, ou seja, não somente circulava um sabre, como junto com ele viajavam, inconstantes e intangíveis, valores e significados em disputa.

Apesar de o sabre ter retornado ao país e ingressado no $\mathrm{MHN}$ entre significados diferentes de "independência", seu caráter controverso foi suspenso para, assim, interpretá-lo, conservá-lo e exibi-lo unicamente como protagonista e símbolo das lutas que permitiram o nascimento do Estadonação que o MHN mostrava em suas coleções. O sabre permaneceria neste museu até 1963, sem que jamais tenha sido exibido ao lado da polêmica "cláusula terceira".

\section{Um sabre sequestrado como refém}

Em 12 de agosto de 1963, um grupo de membros da chamada Juventud Peronista ingressou no MHN, tendo como único propósito apoderar-se do sabre, ${ }^{18}$ aliás, deixaram uma mensagem "para o povo argentino". Nesse Comunicado $N^{o} 1$, alegava-se a necessidade de realizar "um ato heróico", sequestrando o sabre para exigir o cumprimento de uma série de condições.

[...], aquele sabre, o puríssimo sabre do pai da pátria, aquele sabre talhado pela glória, aquela síntese viril generosa da pátria ${ }_{1}^{19}$ por milagre da fé, voltará a ser o santo e a marca da libertação nacional. [...] Para isso e a partir de agora, aquele sabre que, um dia, o Libertador, com plena lucidez, legou ao brigadier general Juan Manuel de Rosas pela satisfação que lhe deu ver como ele defendeu sua pátria perante as agressões do imperialismo, [aquele sabre] deixou o seu repouso no Museu Histórico Nacional para brilhar, novamente, no magno combate pela reconquista da argentinidade. Desde hoje, o sabre [...] ficará custodiado pela juventude argentina, representada pela Juventude Peronista. [...] O povo argentino não deve albergar preocupação nenhuma: o sabre curvo ${ }^{20}$ de San Martín será cuidado como se fosse o coração das nossas mães; Deus queira que, em breve, possamos reintegrá-lo a seu merecido descanso. Deus queira iluminar os governantes. Juventude Peronista (Ramallo 1995:95).

Poucos dias depois (17/08/1963), comemorava-se o $113^{\circ}$ aniversário do falecimento de San Martín. As autoridades da Comisión Nacional de Museos, Monumentos y Lugares Históricos aproveitaram essa oportunidade para repudiar publicamente o acontecimento: 
[...] o sabre de San Martín era o seu símbolo [símbolo da liberdade], mas, quando foi pego por mãos inclinadas às ditaduras, torna-se novamente o guia e o lábaro de uma cruzada espiritual, necessária para a redenção dos ressaibos de décadas de opressão. [...] Deste santuário e a partir de agora, dedicar-nos-emos a um compromisso de reparação construtiva; combateremos [...] tudo aquilo que signifique contrariar - por fatos positivos o por indiferença negativa - a trajetória crociana rumo à liberdade, revelada nos museus históricos nacionais e apontada, no alto, pelo Santo da Espada, padroeiro desta casa. ${ }^{21}$

Nesse mesmo dia, a Juventud Peronista lançou seu Comunicado $N^{o} 2$, no qual se enunciavam claramente os requisitos a serem cumpridos para assim devolver o sabre ao MHN. Exigia-se a ruptura com o Fundo Monetário Internacional, o fim da proibição do peronismo como partido político, a devolução do cadáver embalsamado de Eva Perón (até então, desaparecido), o retorno de Juan Domingo Perón à Argentina (na época, exilado na Espanha), o castigo para os militares autores de perseguições e fuzilamentos, e a liberdade de todos os presos políticos - entre outras condições - acrescentando que

[...] rejeitamos as acusações e insultos da imprensa marrom, a serviço do imperialismo petroleiro e da oligarquia do gado, quando afirma que temos pretendido transformar o sabre curvo do libertador em símbolo de um determinado setor político. O sabre do Pai da Pátria está brilhando como sempre brilhou, e como sempre brilhará, ontem, perante os granaderos da Independência, nas mãos do Restaurador [Juan Manuel de Rosas], enfrentando as pretensões dos invasores que queriam manchar a Pátria. Hoje, novamente encabeçando a luta contra a mentira, a infâmia, a entrega e a miséria. ${ }^{22}$

Onze dias mais tarde (28/08/1963), depois de uma súbita e confusa recuperação do sabre através de um membro do Exército, ele foi depositado não no $\mathrm{MHN}$, mas no local do Regimiento de Granaderos a Caballo. ${ }^{23}$ Enquanto o sabre encontrava-se sob "custódia temporária" dos granaderos, a Comisión Nacional de Museos, Monumentos y Lugares Históricos apelava para o disposto na lei $12665,{ }^{24}$ e solicitava a restituição imediata do sabre ao MHN, expressa da maneira seguinte:

[...] O público [que visita o $\mathrm{MHN}$ ] tem aumentado consideravelmente nos últimos dias, chegando, no último domingo, a mais de 5 mil pessoas. [...] Enquanto isso, não achamos conveniente fundamentar, do ponto de vista legal, nem de outros aspectos não menos respeitáveis, o direito de possessão do MHN sobre tão apreciada relíquia [...] A doação foi assim feita à "Nação Argentina", segundo 
as expressões da doadora [Manuelita Rosas] "para que, no MHN, receba a veneração de todos os argentinos". Embora expressa nas formas mais gentis, trata-se de uma doação com cargo, que nem sequer o Congresso tem faculdades para modificar. E esta Comissão Nacional [...] solicita a Vossa Excelência fixar uma data para devolver ao MHN a relíquia subtraída [...]. ${ }^{25}$

Finalmente, em 17 de agosto de 1964 - pouco mais de um ano após o desaparecimento - o sabre foi restituído ao MHN em uma solene cerimônia. Colocado sobre a sela de um cavalo branco, conduzido por um granadero a pé, o sabre de San Martín foi escoltado até o edifício do MHN.

Porém, não permaneceria ali por muito tempo. Em 19 de agosto de 1965, um grupo de jovens armados entrou no MHN, em pleno funcionamento, levando o sabre com eles e sumindo no meio de um tiroteio em que ninguém saiu ferido. O jornal Crónica contou uma versão do acontecido:

[...] o grupo extremista, autor do assalto e roubo, propor-se-ia a tirar do país o sabre curvo do Libertador, via Montevidéu, levando-o para Cuba, como uma mostra de adesão ao regime imperante nesse país (Crónica, 20 de agosto de 1965. Grifo meu).

O jornal La Nación referia-se ao mesmo fato desta maneira:

Resulta evidente o móbil político-social deste fato, perpetrado por elementos de um comando jovem extremista. Nesse sentido, diversifica-se através de diferentes meios o rastreamento policial entre os múltiplos elementos extremistas de tendência peronista, peronista-nacionalista e de atuação pró-castrista, estendendo-se para o interior do país [...] (La Nación, 28 de agosto de 1965. Grifos meus).

Ao mesmo tempo, a Academia Nacional de la Historia declarava:

Perante uma nova subtração do sabre curvo do General San Martín, depositado no MHN, legítimo custódio dos nossos símbolos pátrios, [a Academia] manifesta publicamente seu repúdio pela irreverência cometida contra a mais pura relíquia do passado comum de todos os argentinos. Nem as paixões, nem as ideologias políticas conferem autoridade para desonrar o glorioso sabre do Libertador, que, por sua natureza, constitui um símbolo da união nacional (Ramallo 1995:120-121. Grifo meu ).

Em 4 de junho de 1966 o sabre reapareceu, depois de dez meses de investigação silenciosa feita pelo Servicio de Inteligencia del Ejército, que 
jamais se tornaria pública. Segundo esta instituição, dessa vez o sabre tinha sido roubado, novamente, por membros da Juventud Peronista.

Até 15 de junho de 1967 o sabre permaneceu no Regimiento de Granaderos. Enquanto isso, as autoridades do MHN conservavam a esperança de albergar novamente em seu local a disputada peça. Mas, por decreto do Poder Ejecutivo Nacional (PEN), assinado pelo ditador Juan Carlos Onganía, o sabre ficaria definitivamente em poder do Regimiento de Granaderos "pelo fato de ser uma unidade criada por ele [San Martín], e por ser a que está mais intimamente ligada, no sentir popular, à sua vida gloriosa". ${ }^{26}$ Esta medida provocou a renúncia do diretor do $\mathrm{MHN}$, alegando-se que "a mudança na custódia do sabre curvo do Libertador lesiona princípios legais e históricos que tornam indiscutível sua posse pelo MHN". ${ }^{27}$

O decreto abriu espaço para o debate entre o Regimiento de Granaderos e o Instituto Nacional Sanmartiniano, a respeito de qual instituição contava com maiores direitos sobre o sabre, e qual era a "mais representativa" de San Martín. Um decreto anterior do PEN (26735/50) tinha estabelecido que a função do Instituto Nacional Sanmartiniano era "a guarda e exibição de todos os elementos que pertenceram ao general San Martín, e dos objetos notáveis de sua família", razão pela qual este se declarava com legítimo direito de exigir que o sabre se conservasse naquele local. A este debate somou-se a voz do ex-diretor do MHN, que defendia que "a transferência de qualquer dos elementos constitutivos [do patrimônio do MHN] é uma mutilação do mesmo, ou uma diminuição [...] A mutilação ou diminuição existe, para o Museu Histórico, por seu caráter como Nacional [...]". ${ }^{28}$ Apesar dessas disputas, é o Regimiento de Granaderos a Caballo que continua custodiando, até hoje, o sabre de San Martín, cumprindo-se assim o decretado pelo ditador Onganía.

Faremos aqui um novo salto no tempo. Em 4 de março de 1997 teve lugar, no MHN, um ato comemorativo pelo "Centenário da chegada ao país do sabre do General San Martín". Nessa ocasião, o Regimiento de Granaderos entregou ao diretor do MHN na época uma réplica do sabre; suas palavras foram as seguintes:

A Pátria é um sentimento intangível que nos dá uma ideia de pertença, uma identidade, uma solidariedade e um sentimento afetivo com os elementos de sua vida comum. [...] há momentos em que paramos para lembrar os grandes homens que orientaram a vida comum, e dentre eles surge, nítida, a personalidade do general San Martín [...] Celebramos hoje o centenário da chegada, à terra americana, do sabre curvo que deu a liberdade a meio continente. Nada mais comovedor para um povo do que lembrar este fato, que nos une 
como argentinos, mesmo de distintos partidos, ideologias e procedências. O sabre curvo de San Martín é a imagem tangível da nossa liberdade, da nossa independência e da nossa identidade como povo [...] Todos os objetos desejam voltar [para o MHN], todos, menos um deles. [...] Achamos que o sabre de San Martín, do qual o Museu é o destinatário, deve ser conservado com a veneração e a custódia que merece pelos filhos do Libertador, que foram os seus queridos granaderos. Seus filhos devem continuar guardando a relíquia do seu pai [...] O MHN não aceita réplicas, a não ser para ornamentação e ambientação cenográfica do roteiro histórico. Entretanto, o Museu vai receber uma réplica do sabre, e será colocada em um lugar de privilégio, perante o olhar de milhares de admiradores e cidadãos que vierem nos visitar, do país e do exterior; cuidaremos dele como se fosse o mesmo sabre que empunhara aquele austero e talentoso homem de armas, que só o usou para nobres propósitos [...] Será a única réplica que, para nós, possui o caráter de legítima [...]. (Museo Histórico Nacional. Segunda Época, Año 1, n. 1, pp.85-88, Junio 1998. Grifo meu.)

Farei agora outros apontamentos sobre esse conflituoso período na vida social do sabre. O primeiro desaparecimento, em 1963, torna clara uma nova disputa por sua significação. A Juventud Peronista toma o sabre de San Martín sem questionar, em momento nenhum, quanto ao seu caráter representativo: não se trata de algo valioso para a oposição, mas de um "valor intrínseco" compartilhado por todos os argentinos. A profunda convicção do valor deste objeto evidencia-se na envergadura da troca proposta, isto é, o sabre de San Martín era conservado como uma garantia, era uma espécie de refém poderoso. Como entender que um sabre pudesse valer tanto a ponto de modificar, em troca dele, a realidade político-econômica do país inteiro? Qual o significado posto em jogo, em função do qual seu desaparecimento tornava-se perigoso, apesar de a Juventud Peronista ter manifestado o mesmo respeito para com o sabre e a promessa de uma conservação cuidadosa?

Quando lemos os dois Comunicados da Juventud Peronista, vemos que a ênfase está colocada especialmente em dois significados: soberania e libertação - estes já tinham sido enfatizados por San Martín quando legou seu sabre a Rosas. Em 1963 (perante uma nova ameaça do imperialismo, dessa vez diferente), esses significados foram tomados, mais uma vez, para traçar a linha que conseguiria unir, indefectivelmente, a tríade "San MartínRosas-Perón" em perfeita continuidade (de fato, na letra da famosa "Marcha Peronista" já se exaltava a figura do Libertador). Enquanto a Juventud Peronista, através dessa tríade, invocava a união dos argentinos em face do 
avanço do imperialismo, as autoridades do MHN insistiam na valorização do sabre como símbolo da união dos argentinos "entre si", entendendo por isso que "não poderia fazer parte do vai e vem da política", nem ser utilizado como objeto de disputa entre conflitos partidários.

Dessa maneira, a soberania (um dos conceitos que constituíam seu "valor intrínseco") encontrava-se manipulada de diferentes maneiras e respondia a objetivos de grupos opostos. Mas, ao mesmo tempo, era esse "valor intrínseco", incorporado a um código comum, que permitia estabelecer a base da negociação: além de interpretações divergentes, o fato de falar do "Pai da Pátria" implicava apelar para um sentir nacional, um vínculo de parentesco que estabelecia o coletivo "argentinos-irmãos", libertados por San Martín, herói da independência.

Mais tarde, o destino do sabre constituiu motivo de zelo e conflito, começando assim outro tipo de disputa por sua propriedade, desta vez entre instituições do Estado. Por um lado, o Regimiento de Granaderos afirmava-se como "a melhor custódia" apelando para a criação desta instituição militar pelo próprio San Martín. Por outro lado, o MHN reclamava essa peça apoiando-se nos direitos originários da doação. Quais os interesses que operavam por trás de tais disputas? Qual o "melhor lugar" para o sabre? Qual o significado a respeito de San Martín? Finalmente, o retorno do sabre ao MHN em 1963 foi acompanhado de vários rituais para honrá-lo: como se se tratasse de uma pessoa, o sabre chegou até o MHN montado em um cavalo branco (da mesma maneira que, na pintura histórica, era costume representar San Martín).

O segundo desaparecimento do sabre contém aspectos notavelmente diferentes da vez anterior. Em primeiro lugar, o grupo armado que se apresentou no MHN não se autoidentificou: a vinculação com a Juventud Peronista foi realizada pelo governo e transmitida, dessa maneira, aos meios de comunicação, com o acréscimo de qualificativos tais como extremistas ou subversivos (os quais, no panorama e nos imaginários políticos da época faziam com que fosse perfeitamente possível pensar que se tratava de "tirar o sabre do país" para entregá-lo a Fidel Castro). Mais uma vez, apelou-se para a ideia de união, como na ocasião anterior: a união "ditada pelo sabre" não devia permitir que as rivalidades políticas o tomassem como estandarte de uma parcialidade e, como era isso o que parecia estar acontecendo, a mensagem sagrada do sabre não teria sido nem entendida, nem respeitada: este fato, por si mesmo, colocava os novos usurpadores, mais uma vez, na categoria de profanos.

O breve intervalo entre os dois desaparecimentos abriu espaço para argumentar que "o melhor lugar" para a custódia do sabre seria uma 
dependência militar, e não uma instituição civil. A discussão gerada entre o MHN, o Instituto Nacional Sanmartiniano e o Regimiento de Granaderos, com suas respectivas argumentações, delimita claramente as esferas civil e militar, privilegiando-se esta última a partir da decisão do ditador Onganía.

Trinta anos depois da instalação definitiva, por decreto, no Regimiento de Granaderos, este presenteia o MHN com uma réplica do sabre, que se encontra exposta até os nossos dias. O discurso pronunciado por quem fora, naquela oportunidade, diretor do MHN, merece alguns comentários: referindo-se à chegada do sabre ao país, não fez menção nenhuma à cadeia de complexas doações que permitiram a incorporação do sabre pelo MHN, nem às instâncias controversas de sua recepção em Buenos Aires. Por outro lado, embora mencione o MHN como "destinatário" do sabre, este "deve permanecer" nas mãos do Regimiento de Granaderos. Aliás, os filhos do Pai da Pátria parecem ser, nas palavras dele, somente os granaderos, e não a nação inteira. E, mais uma vez, invoca-se o sabre - embora desta vez replicado - como símbolo de união entre os argentinos. Ao longo do seu discurso, acaba sem explicar os motivos pelos quais a réplica deve ser considerada como se fosse a peça original. Isto parecia depender, simplesmente, da decisão pessoal de um diretor, que poderia definir o modo com que a réplica deveria ser interpretada. Como é possível entender essa mudança de atitude? Como "a relíquia mais pura" do MHN pôde ser trocada por uma imitação, e ser percebida como "a mesma"?

Entendo que decidir dessa maneira a natureza de uma peça de tal envergadura, transformando-a em original, vincula-se diretamente ao prestígio que o MHN desejava manter como "maior museu histórico da nação". Deste modo, reconhecer a ausência de tal objeto, à maneira de "uma amputação ou uma diminuição" (como o fez o diretor deste museu na época da promulgação do decreto de Onganía), implicava aceitar a incompletude do MHN e, consequentemente, questionar seu caráter de custódio da história inteira, completa. Se era verdade que o MHN correspondia ao lugar que "guarda toda a memória nacional e, consequentemente, a identidade dos argentinos", ${ }^{29}$ o sabre replicado deveria, necessariamente, ser considerado como original.

O sabre "autêntico" estava no Regimiento de Granaderos, em um local fechado para o público, e que só podia ser visitado com autorização prévia; enquanto isso, outro sabre encontrava-se no MHN, e era através deste segundo sabre, "considerado como o original", que o público argentino conhecia a história de San Martín e aprendia, com ele, o sentimento de nação. 


\section{Objetos para amar a pátria}

Como pudemos ver na resenha acima apresentada, o sabre circulou entre diferentes regimes de valor em espaço e tempo, em situações sociais específicas que reuniram atores, instituições, ações e projetos políticos muitas vezes discordantes. A partir da figura do próprio San Martín (o dono original do sabre) e das Guerras da Independência (o cenário de atuação do objeto como tal), aparecem, claramente vinculadas a estes as figuras de Juan Manuel de Rosas, Máximo Terrero, Manuelita Rosas e Adolfo P. Carranza. Não obstante - e em escalas e contextos muito diferentes entre si - ao longo do tempo surgem também as disputas entre unitários e federais, a criação e o significado de um museu histórico nacional, a chamada Generación del '80 (com seus participantes e suas ideias), os preparativos para o Centenário da Nação e as relações internacionais, as distâncias entre as instituições civis e as do exército, o regime peronista e sua proibição, as ditaduras militares, a produção da historiografia argentina e o ensino da história — entre outros atores e contextos.

Referindo-me agora às formas de tratamento que o sabre recebeu, posso agrupar brevemente algumas delas, baseando-me nos documentos consultados. Em primeiro lugar, trata-se de um objeto que foi adquirindo vida própria: foi "protagonista" da história argentina; "testemunha muda" da Entrevista de Guayaquil; precisa de "seu merecido descanso" dentro de um museu; "deve-se" à pátria; foi "sequestrado" à maneira de um refém poderoso, e transformado em "ginete" quando andou a cavalo; aliás, possui uma vontade própria, já que "não deseja voltar" ao MHN. Entre essas considerações, aparece também sua dimensão sagrada: da mesma maneira que algumas invocações a San Martín, o sabre manifesta, com sua presença, valores morais e espirituais, encarnando, por exemplo, "a liberdade revelada". ${ }^{30}$

Ele tem, além disso, uma ampla capacidade representativa: é "a imagem de San Martín"; símbolo da liberdade e emblema da independência argentina; objeto de prestígio e reconhecimento político; legitimador das disputas entre unitários e federais; relíquia mais importante do MHN; "síntese viril e generosa da pátria"; objeto de demonstração da linhagem "San Martín/ Rosas/Perón"; garantia de paz e justiça social pela memória que brilha em seu aço. ${ }^{31}$ Ou seja, o sabre parece possuir uma ontologia própria, um caráter sagrado e uma potente capacidade representativa, conseguindo manter, no tempo, o espírito da nacionalidade. Além de "representar" coisas, o poder polissêmico e a eficácia do sabre enquanto símbolo residem também nas posições que foram ocupadas por este objeto em diferentes situações e/ou 
contextos performativos, produzindo sentimentos, mobilizando emoções e desejos (veja-se Turner 1999).

Por mais óbvio que pareça, considero necessário sublinhar que se trata de um objeto, enquanto o resto é uma coleção de atributos colocados por homens e mulheres ao longo do tempo: a história aqui traçada - uma entre muitas outras possíveis - demonstra mais uma vez que o importante não é o objeto em si mesmo, mas as relações que se mantiveram em torno dele. O fato demonstra também a inevitável convergência dos chamados patrimônio material e imaterial, tornando evidente a distância que existe entre as definições e as regulamentações vigentes sobre estas duas classificações, por um lado, e as dimensões levantadas a partir de uma perspectiva antropológica sobre os objetos, por outro - questão que demandaria, por si própria, outro artigo. ${ }^{32}$

Os objetos sozinhos não acumulam dados; não evocam a mesma coisa para todas as pessoas, em qualquer tempo e lugar, nem são "mudas testemunhas" capazes de arbitrar e fechar debates. Tampouco são ornamentos de um relato, ou "objetos objetivos" (como defendia o anterior diretor do MHN; veja-se Roca 2003:45). São objetos constituídos e atravessados por relações sociais, portanto, veículos acompanhados de interpretações e representações ao longo de sua história de vida; eles remetem para a produção de sentidos através dessas interações sociais, mobilizando-se, a cada contexto, significados capazes de criar sentidos e valores, aptos para funcionar como meios de orientação para que se compreendam realidades presentes ou passadas.

Neste sentido, o sabre parece ter sido apresentado como um objeto de afirmação histórica, evocando unicamente as instâncias do nascimento da pátria. Mas, como pudemos ver no relato desenvolvido na primeira parte, além de ter participado das batalhas contra os espanhóis com sua qualidade intrínseca de "arma branca", o sabre participou também, até nossos dias, de outro tipo de batalhas, travadas em torno da sua propriedade, dos seus significados, e da propriedade e/ou administração desses significados. Não obstante, o MHN - centro produtor e possuidor de emblemas - parece ter sido a instituição que dirigiu ambos os empreendimentos, gerindo, em primeiro lugar, a forma de dar a conhecer a peça original, de 1897 até 1963, e conduzindo, mais tarde, a percepção do público em torno de uma réplica, "a única que possuía o caráter de legítima".

Em outros trabalhos anteriores (Roca 2003, 2008a, 2008b) analisei as práticas expositivas do $\mathrm{MHN}$, exercidas até $2005 .{ }^{33}$ Até esse momento, as sucessivas autoridades desta instituição mantiveram a vocação inicial projetada quando da criação do museu, em 1889, organizando um relato histórico-museológico conforme os interesses da classe dirigente (que, por 
sua vez, tinha doado suas próprias coleções para ilustrá-lo). Basicamente, ao longo das décadas, foi oferecida uma única versão da história argentina, totalizante, centralizada em Buenos Aires e focalizada quase exclusivamente no século XIX. Aquele discurso visual apresentava o nascimento e a formação de um Estado nacional, no qual não tinham participação nem os povos indígenas, nem os negros, nem os imigrantes. A história dessa sociedade portenha e branca foi exibida, aliás, como uma transmissão cronológica de personagens e eventos consagrados; o museu custodiava a "glória nacional" e seus objetos eram tratados em termos de "relíquias", portadoras de valores intrínsecos (Dujovne 1995; Roca op. cit.). Tal como seus heróis, tratava-se de objetos "puros", sem contradições; ao longo das vitrines, eles conseguiam exibir o sentimento patriótico e conservar a memória nacional.

Conforme os documentos examinados, as primeiras autoridades deste museu consideraram o sabre de San Martín como "o" emblema das lutas pela independência da República Argentina, construindo museologicamente uma relação indissolúvel e unívoca entre objeto e significado. Junto com o sabre, vários objetos deste museu fizeram - e fazem - parte de um "patrimônio histórico nacional", pelo fato de terem sido vinculados a diferentes segmentos da narrativa historiográfica oficial, através da mediação de agentes e/ou instituições que associavam um determinado objeto a uma figura e/ou a um acontecimento histórico. Essa associação implicava relacionar a coisa em si mesma com um determinado sítio discursivo na história, no qual se assinalava a tal pessoa e/ou fato. A atribuição e a ligação de dois ou mais objetos a um sítio discursivo específico eram aquilo que justificava a sua vizinhança. Deste modo, objetos que aparentemente não tinham nada a ver entre si (de fato, a maioria do material exposto no MHN não foi feito com uma intenção original de ser exibido) acabavam "vinculados" uns aos outros a partir de uma discursividade que os carregava de sentido. Ao mesmo tempo, o próprio museu — devido à sua função representativa, à sua história institucional, à sua arquitetura - proporcionava as estruturas simbólicas em que essa vizinhança se tornava efetiva.

O discurso particular do MHN articulou-se, por si mesmo, como "princípio" de seleção e classificação das peças: os objetos dispersos foram dirigidos para uma narrativa já existente, relacionando-os com ela e atribuindo-lhes um lugar. Entretanto, uma vez inseridos em um sítio discursivo determinado, aquele processo de mediação (através do qual lhes foram incorporados significados e propriedades, isto é, onde "foi produzido" o objeto patrimonial) desaparecia: como uma fusão inevitável, discurso e coisa apresentavam-se inseparáveis, idênticos, querendo significar o mesmo; não havia distância entre as palavras e as coisas, porque a história era "uma", e o que tinha 
acontecido entre elas não era um processo de produção e invenção de sentido, mas uma identificação automática e "transparente", compatível com a magia da história triunfalista que ali era representada.

Devido à sua vocação totalizadora, o MHN pretendeu concentrar e guardar "toda a memória nacional", sem jamais questionar a linearidade de suas construções nem explicitar o caráter esquemático da história que contava de sala em sala. A visão hegemônica que foi divulgada por esse museu apresentava-se, então, como um claro exemplo de que é a ação política que faz coincidir memória, identidade e representação nacional (Chagas 2003:141); através de suas exibições, procurou forjar uma única versão da história do país como explicação do presente dos argentinos.

Nesse lugar de memória (Nora 1984), somente alguns objetos foram conservados e colecionados; como foi analisado mais acima, os dados e/ou as evidências sobre os objetos foram construídos, selecionados e organizados para que digam algumas coisas, e não outras. Essa dimensão, que poderia ser identificada como "imaterial" (isto é, as interpretações e representações sobre os objetos), depende de quem os interroga, por que e para que o faz, e para quem serão dirigidas essas interpretações e representações, sendo necessário então conhecer as eleições e as decisões, sempre políticas, que prevalecem na hora em que esse conhecimento histórico-museológico é produzido. A grande maioria dos argentinos possui uma imagem do herói que corresponde àquela idealizada pela pintura histórica: basicamente, um homem alto e esbelto, com rosto desafiante, montado sempre em um cavalo imaculadamente branco, empunhando seu sabre curvo em sua mão direita e erguendo, com ele, a liberdade da América.

Como parte dos usos sociais das visões a respeito de San Martín, as interpretações sobre o sabre - aplicadas e localizadas social e historicamente definiram, em última instância, não o que o sabre "era", mas como devia ser usado - isto é, tornado político. Por isso, a memória tecida em torno dos "objetos nacionais" não reside em supostas capacidades intrínsecas ou inerentes, criadas por meras contiguidades: são as relações sociais, mantidas até hoje em torno desses objetos que permitem construir seus "dados ou evidências" e, em segundo lugar, são a ênfase, seleção ou ocultamento entre essas relações que constroem determinados dados ou evidências, constituindo assim aquilo que realmente nos resta do passado: uma multiplicidade de interpretações. Interpretações, representações e/ou conhecimentos que, no meu entender, também poderiam ser transformados em "patrimônio" histórico, desde o momento em que sejam postos em circulação e/ou habilitados para seus usos sociais, sendo possível, então, traçar uma diversidade de vínculos histórico-afetivos entre "um sabre" — que já não possuiria um 
significado unívoco - e as diferentes formas de fazer e/ou de se sentir parte da chamada "nação argentina".

A construção explícita desse tipo de patrimônios permitiria não somente a construção de novas realidades - novas maneiras de interpretar o presente - mas também uma democratização da memória, pelo fato de favorecer e/ou estimular uma maior participação social na invenção de cultura, tornando mais claras, ao mesmo tempo, as possibilidades de realização e de intervenção nessa invenção.

Como pudemos acompanhar ao longo da história do sabre de San Martín, as relações sócio-históricas que se articularam posteriormente em torno deste objeto - tanto as metonímicas, estabelecidas entre ele e seu dono, quanto as diversas formas de relação que teve com os outros agentes configuraram conflituosos campos de força, nos quais se lutava por seu significado. O trânsito do sabre por esses campos tem modificado seu status originário, deixando de ser uma simples "arma branca" para carregar uma série de valores atribuídos ao longo do tempo; a mutabilidade de relações e contextos implicou as transformações dos seus valores e significados, razão pela qual não poderíamos interpretar o sabre como uma entidade "estável" como parecem sugerir a historiografia tradicional e as representações criadas a partir da pintura histórica. Aliás, todas essas instâncias em torno dele conviveram em uma multiplicidade de contextos simultâneos, que ultrapassaram a cidade de Buenos Aires como único eixo e cenário dos acontecimentos, isto é, instâncias que não foram nem vividas nem interpretadas de maneira idêntica no resto do país, e que tampouco invocam os mesmos protagonistas, cenários e significados nas múltiplas memórias históricas desses processos.

O que teria acontecido se o sabre de San Martín não tivesse sido conservado, sem aparecer jamais na cena pública? Acaso teria sido eleito outro objeto como "símbolo por excelência" das Guerras da Independência? De que depende, então, a construção de tal ou qual símbolo, e por que teria sido necessário construí-los? Por que o sabre de San Martín era considerado um objeto "vivo", mas não no sentido das suas transformações? Por que foram enfatizadas algumas relações sociais em torno dele, em detrimento de outras que ficaram no silêncio? Por que sua posse sempre foi entendida como um triunfo entre grupos e/ou instituições opostas? Por que uma réplica do sabre devia ser considerada como o original? Atualmente, qual o tipo de relação que cada um dos argentinos tem com esse objeto? Como o conhecem? Acaso os interpela? Acho que interrogações deste tipo em torno dos chamados "objetos históricos patrimoniais" - problematizando os processos sócio-históricos de formação desses valores culturais nacionais abririam a possibilidade de entender por que teríamos algo a ver com esses 
objetos, pelo fato de se reconhecer que alguma coisa neles ilumina nosso presente, ao mesmo tempo em que nos faz melhorar a percepção da nossa condição de sujeitos históricos, em função de dar conta que a história é mudança, que estamos nela e que continuamos fazendo-a todas as vezes que ativamos essas múltiplas memórias para podermos explicar os nossos também múltiplos - presentes.

Com tudo isso não quero dizer que o sabre de San Martín não constitua um símbolo das Guerras da Independência: certamente o é, porque assim foi construído como uma materialização da nacionalidade. O fato de ter acompanhado San Martín em suas batalhas colocou-o no cenário da historiografia argentina; entretanto, suas chegadas a Buenos Aires, ao MHN e, finalmente, ao Regimiento de Granaderos não foram nem transparentes e/ou "lógicas", nem pacíficas. Ao nos aproximarmos dos seus percursos, vemos que o sabre também participou como objeto polêmico em outro tipo de lutas, lutas estas que igualmente dão conta da história da Argentina, assim como das muitas e diferentes maneiras de "ser argentino".

Recebido em 20 de julho de 2011

Aprovado em 02 de março de 2012

Andrea Roca é doutora em Antropologia Social, integrante do LACED/MN/UFRJ.

E-mail: < andreacmroca@gmail.com>

\section{Notas}

* Este texto tem suas origens na pesquisa que realizei por ocasião de minha monografia de graduação (Roca 2003) e foi progressivamente ampliado através dos debates no curso Troca, reciprocidade e interdependência, ministrado pela falecida professora Lygia Sigaud no PPGAS/MN/UFRJ, e nas discussões mantidas com os membros do Grupo Patrimônio da ABA e da ANPOCS; agradeço-lhes aqui seus aportes e comentários. Traduzi para o português todas as fontes documentais utilizadas neste trabalho, indicando, não obstante, as referências de suas publicações em espanhol; tais fontes aparecem citadas por diferentes autores (Quesada 1899, 1902; Otero 1932; Ortiz de Rozas 1950; Ramallo 1995 [1963]), e foram consultadas por mim na Biblioteca Nacional da República Argentina, no arquivo do Museo Histórico Nacional e na Biblioteca del Congreso de la Nación. 
1 "Museo del Regimiento de Granaderos a Caballo General José de San Martín", inaugurado em março de 1968.

${ }^{2}$ A seguir, acrescenta-se: "A decidida proteção que deu ao Exército dos Andes sua padroeira e generala, nossa Mãe e Senhora do Carmen, é visível demais (do General José de San Martín - Agosto 12, 1816)".

${ }^{3}$ De dimensões pequenas, as outras salas deste museu militar são chamadas "Iconografía Sanmartiniana" e "San Martín y sus jefes"; nelas, exibem-se retratos da época, pinturas temáticas, elementos que pertenceram a San Martín e a seus oficiais, uniformes antigos, armas e documentos.

${ }^{4}$ Refiro-me desta forma aos bens culturais de pertença coletiva, associados ao sentimento nacional, resultando por isso preservados, revitalizados e divulgados como representações materiais da cultura que supostamente encarnam (Abreu 2003; Guimaraens 1998).

${ }^{5}$ Em 1820, antes de partir para combater pela independência do Peru, o herói declarava que "o general San Martín jamais vai derramar o sangue dos seus compatriotas, e só vai desembainhar o seu sabre contra os inimigos da independência da América do Sul" (22/07/1820; em Ibarguren, Carlos. 1933. Juan Manuel de Rosas: su vida, su drama, su tiempo. Buenos Aires: Anaconda. p. 148; citado em Ramallo 1995:26). O modelo ético representado por San Martín foi tal que, até aproximadamente 1950, entre as leituras obrigatórias da escola primária do Estado encontravam-se as "Máximas de San Martín para sua filha Merceditas": no currículo escolar, as sentenças do herói eram transmitidas como um "manual" de atitudes e comportamentos.

${ }^{6}$ Segundo o historiador José Luis Romero (1956:104-110), depois da Revolução de Maio de 1810, os sentimentos patrióticos se manifestaram a partir de uma diversidade de formas locais, alinhando-se em diferentes tendências políticas que, em geral, uniram-se sob o chamado federalismo, entendido como a reunião dos estados provinciais livres em um Estado nacional. Mais tarde, passadas as guerras contra o inimigo espanhol, surgiram outros conflitos motivados principalmente pela rivalidade das províncias no controle dos rios navegáveis, e/ou estimulados pelo ódio ao liberalismo exógeno dos unitários representantes de Buenos Aires, com sua centralização de recursos. Por toda parte surgiram caudilhos federais que fortaleceram sua autoridade levantando a bandeira da autonomia provincial, querendo evitar a preponderância da capital portenha. Em Buenos Aires, no seio do grupo liberal e especialmente entre os conservadores, o federalismo foi interpretado como uma expressão de selvageria e anarquia, devendo-se lutar violentamente contra ele.

${ }^{7}$ A respeito disso, o importante político e ideólogo unitário Juan Bautista Alberdi escrevia: "Ela [Manuelita Rosas] e sua família podem se consolar com um fato: enquanto [na Argentina] se erguem altares para San Martín, o seu sabre está em Southampton, servindo como um troféu monumental ao túmulo de Rosas, entregue a Rosas pelo próprio herói..." (Paris, 27/06/1887. Carta citada em Victorica, 
Ricardo. 1912. Errores y omisiones de la obra "Bibliografía del General José de San Martín y de la Emancipación Sudamericana". Buenos Aires: Comercio. pp. 26-28; veja-se Ramallo op.cit.:36).

${ }^{8}$ De maneira similar a outras figuras históricas - tais como Bartolomé Mitre (1821-1906), Justo José de Urquiza (1801-1870), ou Domingo Faustino Sarmiento (1811-1888) - San Martín "sabia" acerca da magnitude histórica de sua pessoa e, durante os últimos anos de vida, dedicou-se com especial interesse a reunir tanto seus objetos quanto sua correspondência; por isso minha afirmação de "saber-se transcendental". No prólogo à Historia de San Martín, seu biógrafo Bartolomé Mitre escrevia: "Uma das mais ricas fontes de informação autêntica [...] tem sido o arquivo do próprio General San Martín [doado por sua neta]. Quando confiou-me esses papéis, essa distinguida senhora me disse que deixava sob o meu discernimento decidir quais eram de verdadeira utilidade e quais deviam se destruir. Felizmente, entre eles não há papéis que devam ser destruídos; sem dúvida, o seu primitivo possuidor teve a generosidade de fazê-lo por si mesmo [...] conservando unicamente os que pudessem ser úteis à história" (Mitre, Bartolomé. 1950 [1887] Historia de San Martín y de la emancipación sudamericana. Buenos Aires: El Ateneo. p. 12).

${ }^{9}$ Para analisar os laços de reciprocidade criados através dos objetos e os acréscimos sobre seu valor social, tornam-se imprescindíveis os clássicos trabalhos do Bronislaw Malinowski e Marcel Mauss (Malinowski, B. 1995 [1922]. Los argonautas del Pacífico Occidental. Barcelona: Ediciones Península; Mauss, M. 1971 [1923-24]. "Ensayo sobre el Don" In: Sociología y Antropología. Tecnos: Madrid).

${ }^{10}$ Existem numerosos depoimentos da época contra esse legado de San Martín. Domingo F. Sarmiento, por exemplo, escreveria em 1854: "A desculpa pela inexata apreciação dos fatos e dos homens está na hora da sua morte [...] na ausência de 36 anos do teatro dos acontecimentos, e nas fragilidades do juízo de um homem no seu período septuagenário" (Sarmiento, Domingo F. 1898. Obras Completas, Tomo III. Buenos Aires: Luz del Día; em Ramallo op.cit.:32). É importante destacar aqui que San Martín não escreveu seu testamento "à hora da morte", mas seis anos antes.

${ }^{11}$ Citado no folheto institucional do MHN, editado em 2001.

${ }^{12}$ Vejam-se os "Documentos sobre la Creación y Nacionalización del Museo Histórico, 21 de Mayo de 1889". In: El Museo Histórico. Tomo I. Entrega I. 1892. Buenos Aires: Guillermo Kraft Editor.

${ }^{13}$ Carranza fazia parte do grupo liberal conhecido como Generación del '80; por sua vez, alguns dos seus membros também faziam parte do "Directorio" do MHN, tais como Julio Argentino Roca e Bartolomé Mitre. Estes foram presidentes da República Argentina: o primeiro entre 1880-1886 e 1898-1904; o segundo, entre 1862-1868.

${ }^{14}$ Para acompanhar os inventários e os percursos das gestões de Carranza, veja-se: "Prospecto". In: El Museo Histórico. Tomo I. Entrega I. 1892. Buenos Aires: Guillermo Kraft Editor. 
${ }^{15}$ Quiçá a ausência mais significativa tenha sido a de Bartolomé Mitre, biógrafo de San Martín.

${ }^{16}$ Jornais La Prensa, El Tiempo, El Día; 5 de março de 1897. Neste último, manifestava-se que "os poderes públicos têm se mostrado quase estranhos, como se, em vez de ser o sabre que venceu em Chacabuco e Maipo, tivesse se tratado de um objeto qualquer" (Grifo meu).

${ }^{17}$ Esta maneira de se referir ao MHN tem sido utilizada inúmeras vezes, não só por Carranza em finais do século XIX, mas também - como será abordado mais adiante - nas visitas guiadas do MHN, até 2005 .

${ }^{18}$ Jornal La Prensa, 13 de agosto de 1963: “que o propósito daqueles foi só apoderar-se do sabre de San Martín: não tocaram em nenhum outro objeto depositado no museu" (Grifo meu).

${ }^{19}$ Encontramos aqui um paralelo com o apontado por Michael Taussig, quando se refere ao sabre do herói venezuelano Simón Bolívar como "o falo do Estado bolivariano" (1991:512). Em janeiro de 1974, o sabre de Bolívar também foi subtraído; nessa oportunidade, por um grupo guerrilheiro, identificado como "M-19". Quando foi preso, o comandante do grupo declarou: "Não é uma arma velha, tenho na minha mão a verdadeira história do nosso país [...] Se você empunhar esse sabre, você vai se sentir Bolívar... sente-se a presença do Libertador, e sente-se um enorme compromisso" (Citado em Taussig, op.cit. Grifo meu).

${ }^{20}$ Até hoje, quando se faz alguma referência ao sabre de San Martín, este é nomeado como "sabre curvo", e assim aparece em todos os documentos citados neste artigo.

${ }^{21}$ Expressões do presidente dessa Comisión, Dr. Jorge A. Mitre. Jornal La Nación, 18 de agosto de 1963. Cabe apontar aqui que, em 6 de agosto de 1950, uma resolução deste organismo havia designado San Martín como "padroeiro" do MHN.

${ }^{22}$ Em Ramallo, op.cit.:96-97. Note-se como, neste Comunicado, estabelece-se a seguinte continuidade: "ontem" com o Pai da Pátria, San Martín; a seguir, "nas mãos do Restaurador", Rosas, e por último, com a Juventud Peronista, construindo desse modo a tríade patriótica invocada pelo peronismo, "San Martín-Rosas-Perón". A respeito da visão desse partido político sobre tal continuidade, veja-se Rodolfo Ortega Peña e Eduardo Luis Duhalde. 1968. San Martín y Rosas. Política nacionalista en América. Buenos Aires: Editorial Sudestada.

${ }^{23}$ Atualmente, sabe-se que a subtração do sabre por parte da Juventud Peronista tinha como objetivo enviar o sabre a Perón (na época, exilado na Espanha); também foi um golpe de efeito para "revitalizar a resistência peronista" e repudiar os resultados das eleições presidenciais daquele ano, enquanto o peronismo estava proscrito (Clarín, 12 de agosto de 2008; entrevista a Osvaldo Agosto, um dos "jovens peronistas" que roubaram o sabre). 
${ }^{24}$ Nesta lei, através da qual era criada a Comisión em 6 de agosto de 1940, dava-se a essa instituição a custódia e a conservação dos bens históricos e artísticos de propriedade da Nação.

${ }^{25}$ Carta publicada pelo jornal La Nación, 6 de setembro de 1963.

${ }^{26}$ Boletín Oficial. Decreto 8756/67, 11 de novembro de 1967.

${ }^{27}$ Ex-capitão de navio Humberto Burzio. Jornal La Prensa, 28 de novembro de 1967.

${ }^{28}$ Jornal La Nación, 30 de novembro de 1967. Grifo meu. Quanto à divisão do patrimônio do MHN, o ex-diretor Burzio comentava: "Resultado dessa política seria ter muitas pátrias pequenas que falassem de uma história fragmentada, mas não da maior, da nacional, como foi sonhada pelos nossos heróis" (Grifos meus).

${ }^{29}$ Palavras do diretor, no ato de reinauguração do MHN, em 11 de agosto de 1997. In: Museo Histórico Nacional. Segunda Época, Año 1, n. 1, p. 92, Junio 1998. Grifo meu.

${ }^{30}$ Poderíamos lembrar aqui a análise de Émile Durkheim: as partes do "ser sagrado" possuem a capacidade de evocar os mesmos sentimentos que este, como "um todo", rememora. Assim, o ser sagrado pode se dividir inúmeras vezes, permanecendo idêntico a si mesmo em cada uma das suas partes; "um simples fragmento de bandeira representa a pátria do mesmo modo que a própria bandeira: pelo mesmo, é sagrado com título e grau idênticos" (Durkheim 1968:215).

${ }^{31}$ Para algumas das análises sobre a arbitrariedade do símbolo e suas capacidades de significação, vejam-se Turner 1999; Gilbert Durand. 1971. La imaginación simbólica. Buenos Aires: Amorrortu; Paul Ricoeur. 1988. Hermenéutica y Acción. Buenos Aires: Docencia.

${ }^{32}$ Segundo a UNESCO, o patrimônio imaterial estaria definido como as práticas, as representações, as expressões, os conhecimentos e as técnicas - junto com instrumentos, objetos, artefatos e lugares culturais que lhes são associados - que as comunidades, os grupos e, em alguns casos, os indivíduos reconhecem como parte integrante de seu patrimônio cultural, patrimônios que são transmitidos de geração em geração, e que são constantemente recriados pelas comunidades e pelos grupos, tanto em função de seu ambiente quanto através de sua interação com a natureza e com sua história; tratar-se-ia de práticas, representações, expressões, conhecimentos e técnicas capazes de gerar um sentimento de identidade e continuidade (veja-se Convention For the Safeguarding of the Intangible Cultural Heritage. Paris: UNESCO, 17/10/2003). Longe de poder polemizar aqui sobre a amplitude e a forma vaga desta problemática definição, interessa-me somente utilizá-la para, à luz da minha própria pesquisa, tornar ainda mais evidentes os complexos contornos patrimoniais do sabre. 
${ }^{33}$ As propostas de mudança da nova direção do MHN, presente desde dezembro de 2005, aspiram fazer do museu um lugar de memória dinâmica, em que a recuperação do passado constitua uma ferramenta ativa para a compreensão do presente; o museu tem deixado de ser um mausoléu colecionador de relíquias para tornar-se um espaço de memória crítica, uma instituição produtora de um conhecimento histórico que admite variações. Assim sendo, as novas autoridades entendem que não se trata de trocar uma história por outra, mas de colocar permanentemente em questão o significado e o sentido da história, e de impedir sua cristalização.

\section{Referências bibliográficas}

ABREU, Regina. 2003. "A emergência do patrimônio genético e a nova configuração do campo do patrimônio". In: R. Abreu \& M. Chagas (orgs.), Memória e patrimônio. Ensaios contemporâneos. Rio de Janeiro: DP\&A. pp. 30-45.

APPADURAI, Arjun. 1986. "Introduction: commodities and the politics of value". In: The social life of things. Cambridge: Cambridge University Press. pp. 3-61.

BOURDIEU, Pierre. 1998. O poder simbólico. Rio de Janeiro: Bertrand Brasil.

CHAGAS, Mário. 2003. "Memória política e política de memória" In: R. Abreu e M. Chagas (orgs.), Memória e patrimônio. Ensaios contemporâneos. Rio de Janeiro: DP\&A. pp.141-174.

DUJOVNE, Marta. 1995. Entre musas y musarañas: una visita al museo. Buenos Aires: Fondo de Cultura Económica.

DURKHEIM, Émile. 1968. Las formas elementales de la vida religiosa. Buenos Aires: Shapire.

GUIMARAENS, Dinah. 1998. A reinvenÇão da tradição: ícones nacionais de duas Américas. Tese de Doutorado, PPGAS-Museu Nacional, UFRJ.
KOPYTOFF, Igor. 1986. "The cultural biography of things: commoditization and process" In: A. Appadurai (org.), The social life of things. Cambridge: Cambridge University Press. pp. 64-91.

NORA, Pierre. 1984. "Entre mémoire et histoire: la problématique des lieux". In: Les lieux de mémoire. Paris: Gallimard. pp. XVII-XLII.

ORTIZ DE ROZAS, Nicolás. 1950. El sable de San Martín. Cuándo y cómo retornó al país. Referencias y datos para la historia. La Plata: Grial.

OTERO, José Pacífico. 1932. Historia del libertador Don José de San Martín. Buenos Aires: Anaconda. T. IV (18221850).

QUESADA, Ernesto. 1899. Las reliquias de San Martín y su iconografía. Buenos Aires: Bredahl. . 1902. Las reliquias de San Martín. Estudio de las colecciones del Museo Histórico Nacional. Buenos Aires: Imprenta Europea de M. A. Rosas.

RAMALLO, José María. 1995 [1963]. Historia del sable de San Martín. Buenos Aires: Instituto Nacional Sanmartiniano. ROMERO, José Luis. 1956. Las ideas políticas en Argentina. Buenos Aires: Fondo de Cultura Económica. 
ROCA, Andrea. 2003. La vecindad de los objetos: lo propio y lo ajeno en el estudio de los sistemas clasificatorios del Museo Histórico Nacional y el Museo Etnográfico. Monografia de Graduação em Ciências Antropológicas, Facultad de Filosofía y Letras, Universidad de Buenos Aires. 2008a. "As classificações e as abordagens dos acervos no Museu Histórico Nacional da República Argentina". Anais do Museu Histórico Nacional, 40:437-456.

. 2008b. "Classificar, nomear, representar: objetos e palavras para construir a nação argentina em um museu" In: M. Chagas, R. Zamorano Bezerra, S. Fassa Benchetrit (orgs.), A democratização da memória: a função social dos museus ibero-americanos. Rio de Janeiro: Museu Histórico Nacional, v. 1, pp. 105-124.

TAUSSIG, Michael. 1991. "La magia del Estado: María Lionza y Simón Bolívar en la Venezuela contemporánea" In: Manuel Gutiérrez et al. (eds.), De palabra y obra en el Nuevo Mundo 2. Encuentros interétnicos. México: Siglo XXI. pp. 489-517.

THOMAS, Nicholas. 1991. Entangled objects. Exchange, material culture and colonialism in the Pacific. Cambridge, London: Harvard University Press.

TURNER, Victor. 1999 [1967]. La selva de los símbolos. Madrid: Siglo XXI.

\section{Outras fontes}

Boletín Oficial de la Repúblca Argentina Gaceta del Museo Histórico Nacional Jornal La Prensa Jornal El Tiempo Jornal El Día Jornal La Nación Jornal Crónica Revista Museo Histórico Nacional 


\section{Resumo}

A partir da análise das complexas redes de intercâmbios, reciprocidades e interdependências tecidas em torno de um objeto histórico considerado emblemático na Argentina, o sabre do General José de San Martín (1778-1850), o artigo visa refletir sobre a produção social de sentidos, valores e significados nos objetos que integram os chamados "patrimônios históricos nacionais". Identificando as dimensões imateriais que parecem acompanhar esses acervos, problematizar-seá sobre as possibilidades abertas pela pesquisa antropológica a respeito dessa classe particular de objetos.

Palavras-chave Objetos, Patrimônios nacionais, História argentina.

\section{Abstract}

Based upon an analysis of the complex network of exchanges, reciprocities and interdependencies woven around a historical object that is considered to be emblematic in Argentina - the saber of General José de San Martín (1778-1850) the present article reflects upon the social production of meanings, values and understandings of objects that are part of "national historical patrimonies". Identifying the immaterial dimensions which seem to accompany these objects, we discuss the possibilities that anthropological research opens with regards to this particular class of objects.

Key words Objects, National patrimony, Argentine history. 